Article

\title{
A Combined Fuzzy-AHP and Fuzzy-GRA Methodology for Hydrogen Energy Storage Method Selection in Turkey
}

\author{
Alev Taskin Gumus ${ }^{1, *}$, A. Yesim Yayla ${ }^{2}$, Erkan Çelik $^{1}$ and Aytac Yildiz ${ }^{3}$ \\ 1 Department of Industrial Engineering, Mechanical Faculty, Yildiz Technical University, \\ İstanbul 34349, Turkey; E-Mail: erkcelik@yildiz.edut.tr \\ 2 Department of Mechanical Engineering, Faculty of Technology, Marmara University, \\ İstanbul 34722, Turkey; E-Mail: yayla@marmara.edu.tr \\ 3 Automotive Technologies Program, Amasya Vocational School, Amasya 5100, Turkey; \\ E-Mail: aytac.yildiz@amasya.edu.tr \\ * Author to whom correspondence should be addressed; E-Mail: ataskin@yildiz.edu.tr; \\ Tel.: +90-212-383-2898; Fax: +90-212-258-5928.
}

Received: 24 April 2013; in revised form: 30 May 2013 / Accepted: 13 June 2013 /

Published: 20 June 2013

\begin{abstract}
In this paper, we aim to select the most appropriate Hydrogen Energy Storage (HES) method for Turkey from among the alternatives of tank, metal hydride and chemical storage, which are determined based on expert opinions and literature review. Thus, we propose a Buckley extension based fuzzy Analytical Hierarchical Process (Fuzzy-AHP) and linear normalization based fuzzy Grey Relational Analysis (Fuzzy-GRA) combined Multi Criteria Decision Making (MCDM) methodology. This combined approach can be applied to a complex decision process, which often makes sense with subjective data or vague information; and used to solve to solve HES selection problem with different defuzzification methods. The proposed approach is unique both in the HES literature and the MCDM literature.
\end{abstract}

Keywords: hydrogen energy storage; fuzzy-AHP; fuzzy-GRA

\section{Introduction}

Turkey is in a position of having a wide range of energy sources, but it is also a country with a wide gap in its energy demands [1]. It imports more than $60 \%$ of its energy demand and this ratio has been 
increasing continuously. This situation causes the country to seek new and renewable alternative energy resources. Among the alternative sources, solar, wind, biomass and hydrogen are unlimited, and among these alternatives, due to its numerous features, the best one is hydrogen energy (HE) [2].

Alternative sources to produce hydrogen fuel in Turkey are hydraulic, solar, wind, sea-wave, geothermal and nuclear energies. From the perspective of developing countries and countries at technologically transitional stage, it seems that, in the long range, a photo-voltaic solar-hydrogen system seems to be the right choice. One of the advantages of Turkey is that it has a rather long Black Sea coastline for preserving stored HE in chemical form in the seabed [3].

It is rather important to note that the United Nations Industrial Development Organizations - International Centre for Hydrogen Energy Technologies (UNIDO-ICHET) was established in Istanbul and this provides the country with considerable opportunities. Turkey has a chance to follow all the technological progress and it could also provide the county an opportunity to export its know-how and transfer technology on the subject. With the help of the UNIDO-ICHET, Turkey could be one of the centre in the world to produce the hydrogen related technologies and products [4].

It is important not to miss the fact that as the national petroleum production does not meet the needs of the country's consumption, a remarkable amount of the nation's petroleum consumption is imported, causing an increasing detrimental gap in the nation's economic development. At that stage, among the alternative fuels, hydrogen has an important potential role to play. Currently, the solution of the high storage costs, which is the most difficult hurdle in HE, will be a big advantage for a county. This advantage is mainly due to hybrid hydrogen technology together with the existence of remarkable amount of the world's boron mining reservoirs in Turkey [5].

For both fixed and portable applications, storage of hydrogen in an efficient and reliable manner is required. Hydrogen can be stored in tanks as gas or liquid in the pure form, physically in the form of nanotubes or chemically as a hydride.

In this paper, based on expert opinions and literature review we aim to determined the most appropriate HES method for Turkey among the alternatives of tank, metal hydride and chemical storage. Thus, we propose a Buckley extension based Fuzzy-AHP and linear normalization based Fuzzy-GRA combined MCDM methodology. This combined approach can be applied to complex decision processes, which often make sense with subjective data or vague information; and used to solve Fuzzy-MCDM problems with different defuzzification methods. In this study, we prefer Buckley's Fuzzy-AHP method. The main advantage of the Fuzzy-AHP method is that it handles multiple criteria with relative ease [6]. Due to the difficulty of providing deterministic preferences for decision makers, perception-based judgment intervals can be used instead. Furthermore It is easier to understand and can effectively handle both qualitative and quantitative data. The use of Fuzzy-AHP reflects human thinking style and does not involve cumbersome mathematics. The proposed approach is unique both in the HES literature and the MCDM literature.

We organize our paper as follows: first, we present a literature review on the use of Fuzzy-AHP and Fuzzy-GRA techniques in the energy field, and especially HE. Then, we define the computational details of Buckley extension based Fuzzy-AHP and linear normalization based Fuzzy-GRA methods. Finally, we realize a numerical application for Turkey, and show the applicability of our methodology with the discussions and conclusions. 


\section{Literature Review}

In this section, we review separately the Fuzzy-MCDM and Fuzzy-GRA literature in the energy field. The main aim here is to mention the gaps in the energy literature based on Fuzzy-MCDM usage and point out the necessity and contributions of the proposed methodology.

\subsection{Fuzzy-MCDM Literature}

There is a wide range usage of Fuzzy-MCDM methods in the literature. Here, the usage of Fuzzy-MCDM methods in energy sector is reviewed. Tzeng et al. [7] apply AHP to determine the relative weights of evaluation criteria. TOPSIS and VIKOR are compared and applied to determine the best compromise alternative fuel buses for public transportation. Wang et al. [8] evaluate coal, petroleum, natural gas, nuclear and renewable energy resources as energy alternatives for China through use of a hierarchical decision model. Kaya and Kahraman [9] aim at determining the best renewable energy alternative for Istanbul by using an integrated VIKOR-AHP methodology. Cavallaro [10] used s Fuzzy-TOPSIS approach for assessing thermal-energy storage in concentrated solar power systems. Kahraman and Kaya [11] utilize Fuzzy-AHP to select the best energy policy for Turkey. Shen et al. [12] present an assessment model for renewable energy sources in Taiwan by using Fuzzy-AHP. A modified Fuzzy-TOPSIS methodology is proposed for the selection of the best energy technology alternative in Kaya and Kahraman's [13] paper. In their study, Erol and Kılkış [14] use an AHP method to facilitate energy resource planning activities. Jin et al. [15] propose an integrated Fuzzy-MCDM process to assess the comprehensive benefits of combined cooling, heating and power (CCHP) systems by considering technology, economy, society and environment as decision criteria. Tsita and Pilavachi [16] present a methodology to evaluate alternative fuels for the Greek road transport sector using AHP. Scott et al. [17] present a detailed review of multi-criteria decision-making methods for bioenergy systems. Daim et al. [18] present a method to evaluate energy storage technologies for investor-owned or public utilities by integrating Fuzzy-Delphi method, AHP and fuzzy consistency matrix.

There are limited number of works in the literature using Fuzzy-MCDM methods for problems related to HE and HES. McDowall and Eames [19] emphasize the HES methods' increase in R\&D funding. McDowall and Eames [20] examine hydrogen economy using a multi-criteria mapping approach to decide between six potential HE systems for the UK. Lee et al. [21] analyze the potential of Korea to be competitive in development of HE technology using a Fuzzy-AHP approach. Chang et al. [22] use Fuzzy-Delphi methodology to evaluate hydrogen production technologies for Taiwan. Lee et al. [23] propose an integrated Fuzzy-AHP and Data Envelopment Analysis (DEA) approach for measuring the relative efficiency of HE technologies for implementing the hydrogen economy. Lee et al. [24] suggest a methodology to prioritize the relative weights of HE technologies and HE technology roadmap as they allocate R\&D budget effectively by using a Fuzzy-AHP. Chang et al. [25] aim to develop an assessment model to evaluate hydrogen fuel cell applications by using Fuzzy-MCDM. Lee et al. [26] applied the integrated Fuzzy AHP and the data envelopment analysis (DEA) for measuring the relative efficiency of the R\&D performance in the national hydrogen energy technology development performance in the national HE technology development. 


\subsection{Fuzzy-GRA Literature}

Here the energy literature using GRA and Fuzzy-GRA methods is reviewed. GRA is a MCDM method, which is originally proposed by Deng [27]. It is applied in solving a variety of MCDM problems. Chang and Lin [28] apply GRA to analyze how energy-induced CO2 emissions from 34 industries in Taiwan are affected by production, total energy consumption, coal, oil, gas and electricity uses. Liang [29] proposes GRA to schedule hydroelectric generations. Chen [30] proposes a combined GRA and AHP method for distribution network reconfiguration. Chiang and Chang [31] present a GRA model for the optimization of the wire electric discharge machining process of particle-reinforced material. Lu et al. [32] propose GRA to evaluate the relative influence of the fuel price, the gross domestic product, number of motor vehicles and the vehicle kilometres of travel per energy increase.

Wang [33] applies Fuzzy-GRA method to evaluate financial performance of Taiwan container lines. Azzeh et al. [34] propose fuzzy set theory with GRA for software effort estimation. Tseng [35] proposes a combined GRA methodology for supplier evaluation of environmental knowledge management capacities. Lee and Lin [36] evaluate and rank energy performances of office buildings by using GRA. Wei [37,38] uses a GRA with intuitionistic fuzzy information in which the information about attribute weights is incompletely known. Lin and $\mathrm{Wu}$ [39] propose a GRA application for analysing the credit risks of banking industry.

Pophali et al. [40] integrate AHP and GRA for optimal selection of full scale tannery effluent treatment plants. Kuo and Liang [41] combine fuzzy VIKOR and GRA methods to evaluate service quality of airports. Zhang and Liu [42] propose a GRA based intuitionistic Fuzzy-MCDM method and apply it to personnel selection problem. Maniya and Bhatt [43] propose a modified GRA and AHP method for selecting automated guided vehicles for material handling. Samvedi et al. [44] combine Fuzzy-AHP and GRA methods for machine tool selection. Chen and Chen [45] propose and integrate DEMATEL, Fuzzy-AHP and GRA. Palanikumar et al. [46] use GRA for optimizing the drilling parameters of composite materials.

\section{The Methods Used in the Proposed Methodology}

In this section, the Buckley extension based fuzzy-AHP algorithm and linear normalization based fuzzy-GRA method are presented.

\subsection{Buckley Extension Based Fuzzy-AHP Algorithm}

In order to deal with the uncertainty and vagueness from the subjective perception and the experience of humans in the decision-making process, decision-makers usually come across with the fact that it is more secure to give interval judgments than fixed-value judgments. This is mainly due to the fact that he/she is unable to explicit about his/her preferences due to the fuzzy nature of the comparison process [47-55].

We utilise Buckley's Fuzzy-AHP algorithm to determine criteria weights since it is easy to extend to the fuzzy case and guarantees a unique solution to the reciprocal comparison matrix and the steps of this approach are relatively easier than the other Fuzzy-AHP approaches. The steps used for the Buckley's Fuzzy-AHP algorithm can be summarized as follows [51]: 
Step 1. Construct pairwise comparison matrices among all the criteria in the hierarchical structure. Assign linguistic terms shown in Equation (1), to the pairwise comparisons by asking which is the more important of each two criteria, such as:

$$
\tilde{M}=\left(\begin{array}{cccc}
1 & \tilde{a}_{12} & \cdots & \tilde{a}_{1 n} \\
\tilde{a}_{21} & 1 & \cdots & \tilde{a}_{2 n} \\
\vdots & \vdots & \ddots & \vdots \\
\tilde{a}_{n 1} & \tilde{a}_{n 2} & \cdots & 1
\end{array}\right)=\left(\begin{array}{cccc}
1 & \tilde{a}_{12} & \cdots & \tilde{a}_{1 n} \\
1 / \tilde{a}_{21} & 1 & \cdots & \tilde{a}_{2 n} \\
\vdots & \vdots & \ddots & \vdots \\
1 / \tilde{a}_{n 1} & \tilde{a}_{n 2} & \cdots & 1
\end{array}\right)
$$

where:

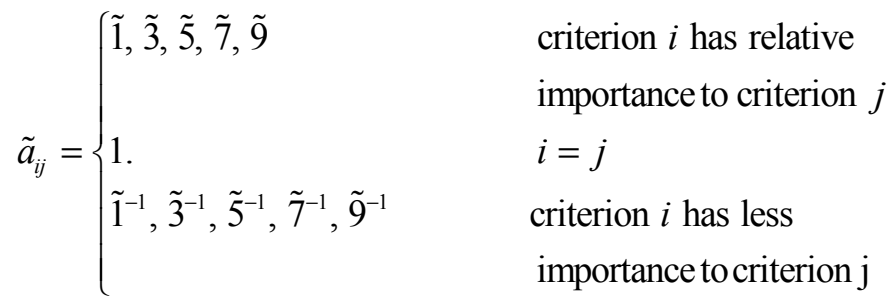

Step 2. Examine the consistency of fuzzy pairwise comparison matrices.

Step 3. Use geometric mean technique to define the fuzzy geometric mean as follows:

$$
\tilde{r}_{i}=\left(\tilde{a}_{i 1} \otimes \tilde{a}_{i 2} \otimes \cdots \otimes \tilde{a}_{i n}\right)^{1 / n}
$$

where $\tilde{a}_{i n}$ is fuzzy comparison value of criterion $i$ to criterion $n$, thus, is geometric mean of fuzzy comparison value of criterion $i$ to each criterion.

Step 4. Calculate the fuzzy weights of each criterion using Equation (4):

$$
\tilde{w}_{i}=\tilde{r}_{i} \otimes\left(\tilde{r}_{1} \oplus \tilde{r}_{2} \oplus \cdots \oplus \tilde{r}_{n}\right)^{-1}
$$

where $\tilde{w}_{i}$ is the fuzzy weight of the ith criterion, can be indicated by $\tilde{w}_{i}=\left(l w_{i}, m w_{i}, u w_{i}\right)$. Here $l w_{i}$, $m w_{i}$, and $u w_{i}$ stand for the lower, middle and upper values of the fuzzy weight of the ith criterion.

Step 5. Utilize Center of Area (COA) method to find out the Best Nonfuzzy Performance (BNP) value (crisp weights) of each criterion by the Equation (5):

$$
B N P \tilde{w}_{i}=\left[\left(u w_{i}-l w_{i}\right)+\left(m w_{i}-l w_{i}\right)\right] / 3+l w_{i}
$$

According to the value of the derived BNP for each of the alternatives, the ranking of the each alternative can then proceed.

\subsection{Linear Normalization Based Fuzzy GRA Method}

The steps of the Fuzzy-GRA algorithm can be outlined as follows [37,38,41]:

Step 1. In the first step, a panel of Decision Makers (DMs) who are knowledgeable about the HES process is established. In a group that has $\mathrm{K}$ decision-makers (i.e., $\mathrm{DM}_{1}, \mathrm{DM}_{2}, \ldots, \mathrm{DM}_{\mathrm{k}}$ ) are responsible for ranking $\left(y_{\mathrm{jk}}\right)$ of each criterion (i.e., $\left.\mathrm{C}_{1}, \mathrm{C}_{2}, \ldots, \mathrm{C}_{\mathrm{n}}\right)$ in increasing order:

$$
\tilde{x}_{i j}=\frac{1}{K}\left[\tilde{x}_{i j}^{1}+\ldots .+\tilde{x}_{i j}^{K}\right]=\frac{1}{K} \sum_{e=1}^{K} \tilde{x}_{i j}^{e}
$$


Step 2. Calculate the normalized decision matrix R. Given $\tilde{x}_{i j}=\left(a_{i j}, b_{i j}, c_{i j}\right)$ the normalized performance rating can be calculated as:

$$
\begin{gathered}
\tilde{r}_{i j}=\left(\frac{a_{i j}}{c_{j}^{+}}, \frac{b_{i j}}{c_{j}^{+}}, \frac{c_{i j}}{c_{j}^{+}}\right), i=1, \ldots, m ; j=1, \ldots, n \text { for } J \in B \\
r_{i j}=\left(\frac{a_{j}^{-}}{c_{i j}}, \frac{a_{j}^{-}}{b_{i j}}, \frac{a_{j}^{-}}{a_{i j}}\right), i=1, \ldots, m \text { and } j=1, \ldots, n \text { for } J \in C \\
\text { where } c_{j}^{+}=\max _{i}\left\{c_{i j}\right\} \text { and } a_{j}^{-}=\min _{i}\left\{a_{i j}\right\} \quad \forall i \quad i=1, \ldots, m
\end{gathered}
$$

Step 3. Determine the reference series. The reference series can be defined as:

$$
\tilde{R}_{0}=\left[\tilde{r}_{01}, \tilde{r}_{02}, \ldots, \tilde{r}_{0 n},\right] \text { where } \tilde{r}_{0 j}=\max \left(\tilde{r}_{i j}\right) j=1, \ldots, n
$$

Step 4. Establish the distance matrix. The distance $\tilde{\delta}_{i j}$ between the reference value and each comparison value is given as:

$$
\tilde{\delta}_{i j}=\left|\tilde{r}_{0 j}-\tilde{r}_{i j}\right|
$$

Step 5. Calculate the fuzzy grey relational coefficient. The fuzzy grey relational coefficient $\tilde{\xi}_{i j}$ is defined as:

$$
\tilde{\xi}_{i j}=\frac{\tilde{\delta}_{\min }+\zeta \tilde{\delta}_{\max }}{\tilde{\delta}_{i j}+\zeta \tilde{\delta}_{\max }} \tilde{\delta}_{\max }=\max \left(\tilde{\delta}_{i j}\right), \tilde{\delta}_{\min }=\min \left(\tilde{\delta}_{i j}\right) \text { and } \zeta \text { resolving coefficient } \zeta \in[0,1] .
$$

Step 6. Estimate the fuzzy grey relational grade $\tilde{\gamma}_{i}$ by the relation:

$$
\tilde{\gamma}_{i}=\sum_{j=1}^{n} \tilde{w}_{j} \tilde{\xi}_{i j}, i=1, \ldots, m
$$

where $\tilde{w}_{j}$ is the weight of the $\mathrm{jth}$ criterion, and $\sum_{j=1}^{n} \tilde{w}_{j}=\tilde{1}$.

Step 7. Apply defuzzification with respect to center of area and $\alpha$-cut method.

\subsubsection{Center-of-Area Defuzzification}

The center-of-area defuzzification method [56] is a way of transforming fuzzy triangular numbers into crisp numbers. This method can determine actual HES priorities and overall scores. For a convex fuzzy number $\tilde{\gamma}$, a real number $x^{*}$ corresponding to its center of area of $\tilde{\gamma}$ can be estimated as [Equation (14)]:

$$
x^{*}=\frac{\int \mu_{\tilde{\gamma}}(x) x d x}{\int \mu_{\tilde{\gamma}}(x) d x}
$$




\subsection{2. $\alpha$-Cut Method}

The $\alpha$-cut method is used in our paper to validate the methodology results and performance of the proposed solution. The $\alpha$-cut method compares two fuzzy numbers $A$ and $B$ in terms of their $\alpha$-cuts $A_{\alpha}=\left[a_{\alpha^{-}}, a_{\alpha^{+}}\right]$and $B_{\alpha}=\left[b_{\alpha^{-}}, b_{\alpha^{+}}\right][57,58]$.

The $\alpha$-cuts can be applied to transform the total weighted performance matrices into interval performance matrices, which provide $\alpha$ left and $\alpha$ right for each alternative as follows:

$$
\tilde{p}_{\alpha}=\left(\begin{array}{c}
\left(\alpha \text { left }_{1}, \alpha \text { right }_{1}\right) \\
\left(\alpha \text { left }_{1}, \alpha \text { right }_{1}\right) \\
\ldots \\
\left(\alpha \text { left }_{1}, \alpha \text { right }_{1}\right)
\end{array}\right) \begin{aligned}
& \alpha \text { left }=\alpha \times(\mathrm{m}-\mathrm{l})+1 \\
& \alpha \text { right }=\mathrm{u}-\alpha \times(u-m)
\end{aligned}
$$

And then the interval matrices are converted into crisp values. It is done by applying the $\lambda$ function and $\lambda$ values are ranged between 0 and 1 :

$$
C_{\lambda}=\left(\begin{array}{l}
C_{\lambda 1} \\
C_{\lambda 2} \\
\ldots \\
C_{\lambda m}
\end{array}\right) C_{\lambda}=\lambda \times \alpha \operatorname{right}+(1-\lambda) \times \alpha \mathrm{left}
$$

Step 8. Rank the alternatives in accordance with the value of grey relational grade; the bigger the value is, the better is among the alternatives.

\section{Numerical Application}

In this section, a numerical application of the described method is presented. For the numerical application a decision making group formed. Three experts, the first one is the director of fuel cell technology and education in UNIDO-ICHET in Turkey, the second one is an academician specialised in renewable energy sources and finally the third one is also an academician specialised in MCDM, are involved in the group. The brainstorming technique is used for qualitative and quantitative group consensus. The group is led by the director of fuel cell technology and education to ensure an effective brainstorming session and the agreement of the group members. The numerical values for most of the alternatives based on each criterion are objective (except reliability), but the importance levels by comparing alternatives with each other may be subjective. By taking into account this probability, we applied expert judgments. With this method, the HES alternatives, which are determined on the basis of the group decision and literature review, are evaluated and the most appropriate one for Turkey is selected by considering several decision criteria.

\subsection{The Methodology}

In this study, a novel methodology integrating Fuzzy-AHP and Fuzzy-GRA approaches is proposed. In this methodology, Fuzzy-AHP is utilized in decision criteria weights evaluation and then the ranking of the alternatives are determined via Fuzzy-GRA approach. Figure 1 shows the details of the proposed methodology. 
Figure 1. The proposed combined Fuzzy-AHP and Fuzzy-GRA methodology.

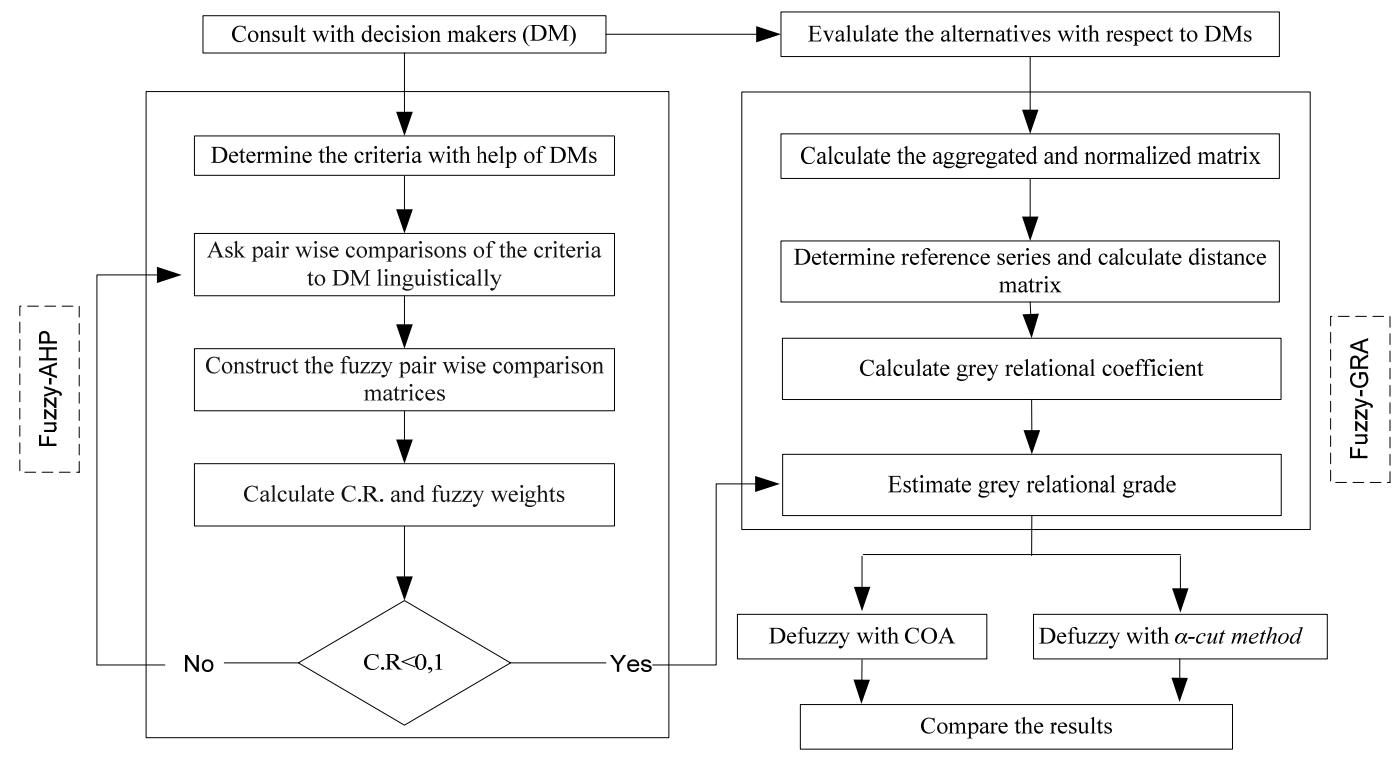

First, the group members (GMs) are asked to compare the criteria considering the effects on selecting the best storage method and the effects on the other criteria in the Fuzzy-AHP phase. In this process, we consider a linguistic scale for relative importance that is shown in Equations $(1,2)$. In the Fuzzy-GRA phase, the GMs are asked to evaluate alternatives considering each criterion. The linguistic scale and corresponding triangular fuzzy numbers are illustrated in Table 1.

Table 1. Linguistic terms and corresponding fuzzy numbers.

\begin{tabular}{cc}
\hline Linguistic variable & Fuzzy number \\
\hline Very Low (VL) & $(1,2,3)$ \\
Low (L) & $(2,3,4)$ \\
Fairly Low (FL) & $(4,5,6)$ \\
Medium (M) & $(5,6,7)$ \\
Fairly High (FH) & $(7,8,9)$ \\
High (H) & $(8,9,10)$ \\
\hline
\end{tabular}

\subsection{The Evaluation Procedure}

During the evaluation procedure, first the criteria hierarchy is structured. Then the combined Fuzzy-AHP and Fuzzy-GRA methodology computations and results are presented. Finally, the final decision is discussed numerically by using grey relational coefficient.

\subsubsection{Determination of Criteria and Alternatives}

In this study, five criteria are used for HES method selection. The group decision is taken into account while determining these criteria and their hierarchy. The hierarchical structure of the proposed methodology is shown in Figure 2. The criteria considered here are weightlessness, capacity, storage loss and leak, reliability and total system cost. 
Figure 2. The HES method selection hierarchy.

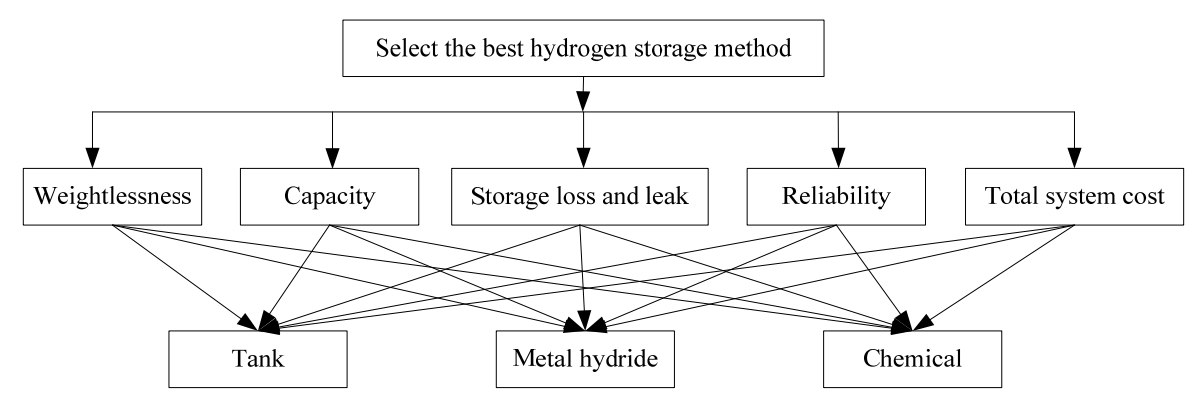

\subsubsection{Application of the Combined Fuzzy-AHP and Fuzzy-GRA Methodology}

The alternatives are consisting of tank (A1), metal hydride (A2) and chemical (A3) storage for Turkey case. And the criteria are determined as weightlessness $(\mathrm{C} 1)$, capacity $(\mathrm{C} 2)$, storage loss and leak (C3), reliability (C4), total system cost (C5). The criteria are non-beneficial except $\mathrm{C} 2$ and $\mathrm{C} 4$. Then criteria influencing the HES are gathered through extensive literature review and decision of GMs. Table 2 summarizes the factors derived from the related literature.

Table 2. Summary of literature review to evaluation criteria.

\begin{tabular}{cc}
\hline Criteria & Sources \\
\hline C1. Weightlessness & Amos [59], Chalk and Miller [61] \\
\hline C2. Capacity & Lee et al. [23,24], Amos [59], İbrahim et al. [60], Chalk and Miller [61] \\
\hline C3. Storage loss and leak & Amos [59] \\
\hline C4. Reliability & Wang et al. [8], Kaya and Kahraman [9], Kahraman and Kaya [11], \\
& Kaya and Kahraman [13], Erol and K1lk1ş [14], Amos [59], İbrahim et al. [60], \\
C5. Total system cost & Wang et al. [8], Kaya and Kahraman [9], Kahraman and Kaya [11], \\
& Kaya and Kahraman [13], Jing et al. [15], McDowall and Eames [19], \\
& Chang et al. [22], Lee et al. [24], Amos [59], Ibrahim et al. [60] \\
\hline
\end{tabular}

The respective terms for describing the importance of material with respect to criteria assessed by GMs are shown in Table 3.

Table 3. Importance of storage alternatives with respect to criteria assessed by decision makers.

\begin{tabular}{ccccccc}
\hline Decision Makers & Alternatives & C1 & C2 & C3 & C4 & C5 \\
\hline \multirow{2}{*}{ DM1 } & A1 & H & H & VL & M & FL \\
& A2 & L & M & VL & H & VL \\
& A3 & L & M & L & FH & VL \\
\hline \multirow{3}{*}{ DM2 } & A1 & FH & H & L & M & L \\
& A2 & L & FH & L & FH & L \\
& A3 & L & M & VL & H & VL \\
\hline \multirow{2}{*}{ DM3 } & A1 & H & M & FL & FH & FL \\
& A2 & L & H & FL & H & VL \\
& A3 & FL & H & L & FH & L \\
\hline
\end{tabular}


The aggregated matrix for storage ratings are calculated by using Equation (6) and it is shown in Table 4.

Table 4. The Aggregated fuzzy values of alternatives.

\begin{tabular}{cccccc}
\hline & C1 & C2 & C3 & C4 & C5 \\
\hline A1 & $(7.67,8.67,9.67)$ & $(7.00,8.00,9.00)$ & $(2.33,3.33,4.33)$ & $(5.67,6.67,7.67)$ & $(3.33,4.33,5.33)$ \\
A2 & $(2.00,3.00,4.00)$ & $(6.67,7.67,8.67)$ & $(2.33,3.33,4.33)$ & $(7.67,8.67,9.67)$ & $(1.33,2.33,3.33)$ \\
A3 & $(2.67,3.67,4.67)$ & $(6.00,7.00,8.00)$ & $(1.67,2.67,3.67)$ & $(7.33,8.33,9.33)$ & $(1.33,2.33,3.33)$ \\
\hline
\end{tabular}

Higher values, that we call positive criteria or beneficial attributes, are desirable and smaller values are named negative criteria or cost criteria. In this normalization method, the cost criterion (C) divided by the minimum value and the benefit criterion (B) is divided by the maximum value of the decision matrix by using Equations (7-9) and the normalized values are shown in Table 5.

Table 5. The normalized matrix.

\begin{tabular}{cccccc}
\hline & C1 & C2 & C3 & C4 & C5 \\
\hline A1 & $(0.21,0.23,0.26)$ & $(0.78,0.89,1.00)$ & $(0.38,0.50,0.71)$ & $(0.59,0.69,0.79)$ & $(0.25,0.31,0.40)$ \\
A2 & $(0.50,0.67,1.00)$ & $(0.74,0.85,0.96)$ & $(0.38,0.50,0.71)$ & $(0.79,0.90,1.00)$ & $(0.40,0.57,1.00)$ \\
A3 & $(0.43,0.55,0.75)$ & $(0.67,0.78,0.89)$ & $(0.45,0.63,1.00)$ & $(0.76,0.86,0.97)$ & $(0.40,0.57,1.00)$ \\
\hline
\end{tabular}

The distance of each candidate from the reference series is calculated by using Equations (10-12). The results are shown in Table 6 .

Table 6. The references series and the distance matrix.

\begin{tabular}{cccccc}
\hline & $\mathbf{C 1}$ & $\mathbf{C 2}$ & $\mathbf{C 3}$ & $\mathbf{C 4}$ & $\mathbf{C 5}$ \\
\hline Reference series & $(0.50,0.67,1.00)$ & $(0.78,0.89,1.00)$ & $(0.45,0.63,1.00)$ & $(0.79,0.90,1.00)$ & $(0.40,0.57,1.00)$ \\
A1 & $(0.29,0.44,0.74)$ & $(0.00,0.00,0.00)$ & $(0.07,0.13,0.29)$ & $(0.21,0.21,0.21)$ & $(0.15,0.26,0.60)$ \\
A2 & $(0.00,0.00,0.00)$ & $(0.04,0.04,0.04)$ & $(0.07,0.13,0.29)$ & $(0.00,0.00,0.00)$ & $(0.00,0.00,0.00)$ \\
A3 & $(0.07,0.12,0.25)$ & $(0.11,0.11,0.11)$ & $(0.00,0.00,0.00)$ & $(0.03,0.03,0.03)$ & $(0.00,0.00,0.00)$ \\
\hline
\end{tabular}

The Fuzzy Grey Relational Coefficient (FGRC) is calculated by applying Equation (12) and it is shown in Table 7. Here, we use the resolving coefficient $\zeta=0,5$ to calculate the FGRC.

Table 7. The fuzzy grey relational coefficient.

\begin{tabular}{cccccc}
\hline & C1 & C2 & C3 & C4 & C5 \\
\hline A1 & $(0.56,0.46,0.33)$ & $(1.00,1.00,1.00)$ & $(0.67,0.53,0.33)$ & $(0.33,0.33,0.33)$ & $(0.67,0.53,0.33)$ \\
A2 & $(1.00,1.00,1.00)$ & $(0.60,0.60,0.60)$ & $(0.67,0.53,0.33)$ & $(1.00,1.00,1.00)$ & $(1.00,1.00,1.00)$ \\
A3 & $(0.84,0.75,0.60)$ & $(0.33,0.33,0.33)$ & $(1.00,1.00,1.00)$ & $(0.75,0.75,0.75)$ & $(1.00,1.00,1.00)$ \\
\hline
\end{tabular}

The fuzzy relational grade is calculated [Equation (13)] with respect to the criteria weights, which are obtained by Fuzzy-AHP [Equations (3-5)], and is shown in Table 8. Also, the consistency ratio (CR) of criteria pairwise comparison matrix is computed to show the consistency of the experts. The $\mathrm{CR}$ value for the defuzzified version of the aggregated fuzzy evaluation matrix is computed as 0.03 
and it is less than 0.10 . The results show that the decision matrix of the proposed hierarchical structure is consistent:

$$
C . I=\frac{\lambda-n}{n-1}=\frac{5,136-5}{5-1}=0,034 ; \quad C . R=\frac{C . I}{R . I}=\frac{0,034}{1,12}=0,030
$$

Table 8. The fuzzy grey relational grade.

\begin{tabular}{cccccc}
\hline & C1 & C2 & C3 & C4 & C5 \\
\hline A1 & $(0.04,0.02,0.02)$ & $(0.07,0.05,0.05)$ & $(0.07,0.07,0.05)$ & $(0.08,0.09,0.09)$ & $(0.34,0.27,0.15)$ \\
A2 & $(0.07,0.05,0.05)$ & $(0.04,0.03,0.03)$ & $(0.07,0.07,0.05)$ & $(0.24,0.26,0.28)$ & $(0.51,0.51,0.46)$ \\
A3 & $(0.06,0.04,0.03)$ & $(0.02,0.02,0.02)$ & $(0.11,0.12,0.14)$ & $(0.18,0.19,0.21)$ & $(0.51,0.51,0.46)$ \\
\hline
\end{tabular}

Here we use each resolving coefficient value to demonstrate that each of them does not affect the results. First, it is assumed that resolving coefficient value $\zeta=0.5$, then the grey relational grade is obtained by COA as $0.9136>0.8796>0.4911$. Similarly, the grey relational grade is obtained by $\alpha$-cuts as $0.9154>0.8812>0.4938$. According to results of COA and $\alpha$-cuts, the ranking order of the three HES is A2 $>$ A3 $>$ A1. The most appropriate HES method for Turkey is metal hydride.

\subsection{Numerical Example Results and Discussion}

First, the concepts of sensitivity analysis are used to verify that the proposed method has rationality and stability, when the conditions of resolving coefficient value and defuzzification methods do not affect the results. This study uses each resolving coefficient value to demonstrate that each of them does not affect the results.

These and the previous results are the same, as shown in Figure 3. The resolving coefficient values on the $\mathrm{x}$ axis and the defuzzified results of the proposed methodology on the $\mathrm{y}$ axis are given. $\mathrm{x}^{*}(\mathrm{COA})$ and $\mathrm{C}_{K}$ ( $\alpha$-cut) method results are shown in the figure, separately. The resolving coefficient values are used to examine the proposed approach between $\zeta=0.1$ and $\zeta=1$. The results show that the variation of the $\mathrm{x}^{*}$ and $\mathrm{C}_{K}$ values of each alternative by using various resolving coefficient values, and also that the ranking orders of the three alternatives are the same, despite changing from a resolving coefficient value of $\zeta=0.1$ to $\zeta=1$. Therefore, this paper can confirm that the results of the ranking orders of all alternatives by using the proposed approach are reliable. Then, this study highlights that various resolving coefficient values do not affect the results of ranking order of the three HESs and it is shown in Table 9 and Figure 3.

Figure 3. Variation analysis of $\zeta$ and defuzzification method value for each alternative (HES).

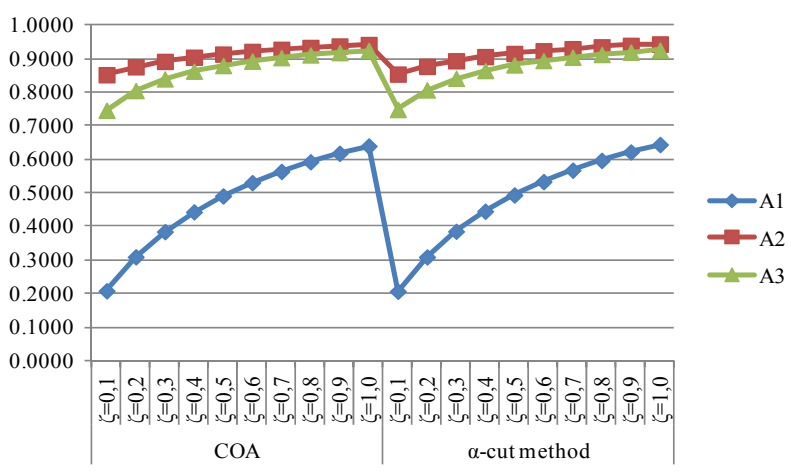


Table 9. The values $\mathrm{x}^{*}$ and $C_{\lambda}$ based on each grey relational coefficient $(\zeta)$.

\begin{tabular}{|c|c|c|c|c|c|c|c|c|c|c|}
\hline & \multicolumn{2}{|c|}{$\zeta=0.1$} & \multicolumn{2}{|c|}{$\zeta=0.2$} & \multicolumn{2}{|c|}{$\zeta=0.3$} & \multicolumn{2}{|c|}{$\zeta=0.4$} & \multicolumn{2}{|c|}{$\zeta=0.5$} \\
\hline & $\mathbf{x}^{*}$ & $C_{\lambda}$ & $\mathbf{x}^{*}$ & $C_{\lambda}$ & $\mathbf{x}^{*}$ & $C_{\lambda}$ & $\mathbf{x}^{*}$ & $C_{\lambda}$ & $\mathbf{x}^{*}$ & $C_{\lambda}$ \\
\hline A1 & 0.2084 & 0.2069 & 0.3097 & 0.3094 & 0.3848 & 0.3858 & 0.4435 & 0.4455 & 0.4911 & 0.4938 \\
\hline A2 & 0.8524 & 0.8539 & 0.8754 & 0.8771 & 0.8917 & 0.8935 & 0.9040 & 0.9058 & 0.9136 & 0.9154 \\
\hline \multirow[t]{3}{*}{ A3 } & 0.7460 & 0.7484 & 0.8047 & 0.8068 & 0.8394 & 0.8413 & 0.8627 & 0.8645 & 0.8796 & 0.8812 \\
\hline & \multicolumn{2}{|c|}{$\zeta=0.6$} & \multicolumn{2}{|c|}{$\zeta=0.7$} & \multicolumn{2}{|c|}{$\zeta=0.8$} & \multicolumn{2}{|c|}{$\zeta=0.9$} & \multicolumn{2}{|c|}{$\zeta=1.0$} \\
\hline & $\mathbf{x}^{*}$ & $\mathbf{x}^{*}$ & $\mathbf{x}^{*}$ & $C_{\lambda}$ & $\mathbf{x}^{*}$ & $C_{\lambda}$ & $\mathbf{x}^{*}$ & $C_{\lambda}$ & $\mathbf{x}^{*}$ & $C_{\lambda}$ \\
\hline A1 & 0.5306 & 0.5339 & 0.5641 & 0.5677 & 0.5929 & 0.5968 & 0.6179 & 0.6221 & 0.6400 & 0.6443 \\
\hline A2 & 0.9213 & 0.9232 & 0.9277 & 0.9296 & 0.9331 & 0.9350 & 0.9378 & 0.9396 & 0.9418 & 0.9436 \\
\hline A3 & 0.8925 & 0.8940 & 0.9027 & 0.9041 & 0.9111 & 0.9124 & 0.9180 & 0.9192 & 0.9239 & 0.9250 \\
\hline
\end{tabular}

\section{Conclusions}

This work is aimed to select the most appropriate HES in Turkey among the alternatives of tank, metal hydride and chemical storage. This is determined based on decision-making group judgment and literature review. Thus, it is proposed to utilize a Buckley extension based Fuzzy-AHP and linear normalization based Fuzzy-GRA combined MCDM methodology.

The contributions of the paper to the literature are as follows: (1) It presents a combined approach that can be applied to complex decision processes, which often make sense with subjective data or vague information; (2) Different defuzzification methods such as COA and $\alpha$-cut are used to solve the HES selection problem at the tactical level; (3) The proposed approach is unique both in the HES literature and the MCDM literature.

As a future suggestion, the hydrogen transportation method selection problem can be analyzed by taking into account the storage method selection problem. Furthermore, different hierarchical and detailed criteria consisting social, political, environmental and market criteria can be incorporated into the study. The proposed model has potential to help with much more complex problems which may or may not have many more hierarchical levels. Finally, a similar problem can be modeled by considering the conditions in different countries outside Turkey.

\section{Acknowledgement}

The authors would like to thank the director of fuel cell technology \& education in UNIDO-ICHET in Turkey for his valuable contribution and discussion.

\section{Conflict of Interest}

The authors declare no conflict of interest.

\section{References}

1. Hamzaçebi, Ç. Forecasting of Turkey's net electricity energy consumption on sectoral bases. Energy Policy 2007, 35, 2009-2016. 
2. Kaya, D. Renewable energy policies in Turkey. Renew. Sustain. Energy Rev. 2006, 10, 152-163.

3. Ültanır, M.Ö. Hydrogen Energy and the Problems to Enter the Hydrogen Energy in Turkey. In Proceedings of Turkish 6th Energy Congress-Technical Session-1 World Energy Council-Turkish National Committee, Izmir, Turkey, 17-22 October 1994; pp. 549-563.

4. Hidrener. Hydrogen Energy [in Turkish]. Available online: http://www.hidrener.com (accessed on 1 April 2012).

5. ETKB [in Turkish]. Available online: http://www.enerji.gov.tr (accessed on 1 February 2012).

6. Kahraman, C.; Cebeci, U.; Ruan, D. Multi-attribute comparison of catering service companies using fuzzy AHP: The case of Turkey. Int. J. Prod. Econ. 2004, 87, 171-184.

7. Tzeng, G.H.; Lin, C.W.; Opricovic, S. Multi-criteria analysis of alternative-fuel buses for public transportation. Energy Policy 2005, 33, 1373-1383.

8. Wang, B.; Kocaoglu, D.F.; Daim, T.U.; Yang, J. A decision model for energy resource selection in China. Energy Policy 2010, 38, 7130-7141.

9. Kaya, T.; Kahraman, C. Multicriteria renewable energy planning using an integrated fuzzy VIKOR \& AHP methodology: The case of Istanbul. Energy 2010, 35, 2517-2527.

10. Cavallaro, F. Fuzzy TOPSIS approach for assessing thermal-energy storage in concentrated solar power (CSP) systems. Appl. Energy 2010, 87, 496-503.

11. Kahraman, C.; Kaya, İ. A fuzzy multicriteria methodology for selection among energy alternatives. Expert Syst. Appl. 2010, 37, 6270-6281.

12. Shen, Y.C.; Lin, G.T.R.; Li, K.P.; Yuan, B.J.C. An assessment of exploiting renewable energy sources with concerns of policy and technology. Energy Policy 2010, 38, 4604-4616.

13. Kaya, T.; Kahraman, C. Multicriteria decision making in energy planning using a modified fuzzy TOPSIS methodology. Expert Syst. Appl. 2011, 38, 6577-6585.

14. Erol, Ö.; Kılkış, B. An energy source policy assessment using analytical hierarchy process. Energy Convers. Manag. 2012, 63, 245-252.

15. Jing, Y.Y.; Bai, H.; Wang, J.J. A fuzzy multi-criteria decision-making model for CCHP systems driven by different energy sources. Energy Policy 2012, 42, 286-296.

16. Tsita, K.G.; Pilavachi, P.A. Evaluation of alternative fuels for the Greek road transport sector using the analytic hierarchy process. Energy Policy 2012, 48, 677-686.

17. Scott, J.A.; Ho, W.; Dey, P.K. A review of multi-criteria decision-making methods for bioenergy systems. Energy 2012, 42, 146-156.

18. Daim, T.U.; Li, X.; Kim, J.; Simms, S. Evaluation of energy storage technologies for integration with renewable electricity: Quantifying expert opinions. Environ. Innov. Soc. Trans. 2012, 3, 29-49.

19. McDowall, W.; Eames, M. Forecasts, scenarios, visions, backcasts and roadmaps to the hydrogen economy: A review of the hydrogen futures literature. Energy Policy 2006, 34, 1236-1250.

20. McDowall, W.; Eames, M. Towards a sustainable hydrogen economy: A multicriteria sustainability appraisal of competing hydrogen futures. Int. J. Hydr. Energy 2007, 32, 4611-4626.

21. Lee, S.K.; Mogi, G.; Kim, J.W. The competitiveness of Korea as a developer of hydrogen energy technology: The AHP approach. Energy Policy 2008, 36, 1284-1291.

22. Chang, P.L.; Hsu, C.W.; Chang, P.C. Fuzzy Delphi method for evaluating hydrogen production technologies. Int. J. Hydr. Energy 2011, 36, 14172-14179. 
23. Lee, S.K.; Mogi, G.; Lee, S.K.; Kim, J.W. Prioritizing the weights of hydrogen energy technologies in the sector of the hydrogen economy by using a fuzzy AHP approach. Int. J. Hydr. Energy 2011, 36, 1897-1902.

24. Lee, S.K.; Mogi, G.; Li, Z.; Hui, K.S.; Li, S.K.; Hui, K.N.; Park, S.Y.; Ha, Y.J.; Kim, J.W. Measuring the relative efficiency of hydrogen energy technologies for implementing the hydrogen economy: An integrated fuzzy AHP/DEA approach. Int. J. Hydr. Energy 2011, 36, 12655-12663.

25. Chang, P.L.; Hsu, C.W.; Lin, C.Y. Assessment of hydrogen fuel cell applications using fuzzy multiple-criteria decision making method. Appl. Energy 2012, 100, 93-99.

26. Lee, S.K.; Mogi, G.; Lee, S.K.; Hui, K.S.; Kim, J.W. Econometric analysis of the R\&D performance in the national hydrogen energy technology development for measuring relative efficiency: The fuzzy AHP/DEA integrateted model approach. Int. J. Hydr. Energy 2010, 35, 2236-2246.

27. Deng, J.L. Introduction to grey system theory. J. Grey Syst. 1989, 1, 1-24.

28. Chang, T.C.; Lin, S.J. Grey relation analysis of carbon dioxide emissions from industrial production and energy uses in Taiwan. J. Environ. Manag. 1999, 56, 247-257.

29. Liang, R.H. Application of grey relation analysis to hydroelectric generation scheduling. Int. J. Electr. Power Energy Syst. 1999, 21, 357-364.

30. Chen, W.H. A grey based approach for distribution network reconfiguration. J. Chin. Inst. Eng. 2005, 28, 795-802.

31. Chiang, K.T.; Chang, F.P. Optimization of the WEDM process of particle-reinforced material with multiple performance characteristics using grey relational analysis. J. Mater. Proc. Technol. 2006, 180, 96-101.

32. Lu, I.J.; Lin, S.J.; Lewis, C. Grey relation analysis of motor vehicular energy consumption in Taiwan. Energy Policy 2008, 36, 2556-2561.

33. Wang, Y.J. Combining grey relation analysis with FMCGDM to evaluate financial performance of Taiwan container lines. Expert Syst. Appl. 2009, 36, 2424-2432.

34. Azzeh, M.; Neagu, D.; Cowling, P.I. Fuzzy grey relational analysis for software effort estimation. Empir. Softw. Eng. 2010, 15, 60-90.

35. Tseng, M.L. Using linguistic preferences and grey relational analysis to evaluate the environmental knowledge management capacity. Expert Syst. Appl. 2010, 37, 70-81.

36. Lee, W.S.; Lin, Y.C. Evaluating and ranking energy performance of office buildings using Grey relational analysis. Energy 2011, 36, 2551-2556.

37. Wei, G.W. GRA method for multiple attribute decision making with incomplete weight information in intuitionistic fuzzy setting. Knowl.-Based Syst. 2010, 23, 243-247.

38. Wei, G.W. Gray relational analysis method for intuitionistic fuzzy multiple attribute decision making. Expert Syst. Appl. 2011, 38, 11671-11677.

39. Lin, S.L.; Wu, S.J. Is grey relational analysis superior to the conventional techniques in predicting financial crisis? Expert Syst. Appl. 2011, 38, 5119-5124.

40. Pophali, G.R.; Chelani, A.B.; Dhodapkar, R.S. Optimal selection of full scale tannery effluent treatment alternative using integrated AHP and GRA approach. Expert Syst. Appl. 2011, 38, 10889-10895. 
41. Kuo, M.S.; Liang, G.S. Combining VIKOR with GRA techniques to evaluate service quality of airports under fuzzy environment. Expert Syst. Appl. 2011, 38, 1304-1312.

42. Zhang, S.F.; Liu, S.Y. A GRA-based intuitionistic fuzzy multi-criteria group decision making method for personnel selection. Expert Syst. Appl. 2011, 38, 11401-11405.

43. Maniya, K.D.; Bhatt, M.G. A multi-attribute selection of automated guided vehicle using the AHP/M GRA technique. Int. J. Prod. Res. 2011, 49, 6107-6124.

44. Samvedi, A.; Jain, V.; Chan, F.T.S. An integrated approach for machine tool selection using fuzzy analytical hierarchy process and grey relational analysis. Int. J. Prod. Res. 2012, 50, 3211-3221.

45. Chen, J.K.; Chen, I.S. A network hierarchical feedback system for Taiwanese universities based on the integration of total quality management and innovation. Appl. Soft Comput. 2012, 12, 2394-2408.

46. Palanikumar, K.; Latha, B.; Senthilkumar, V.S.; Davim, J.P. Analysis on drilling of glass fiber-reinforced polymer (GFRP) composites using grey relational analysis. Mater. Manuf. Proc. 2012, 27, 297-305.

47. Buyukozkan, G.; Feyzioglu, O.; Nebol, E. Selection of the strategic alliance partner in logistics value chain. Int. J. Prod. Econ. 2008, 113, 148-158.

48. Zimmermann, H.J. Fuzzy Set Theory and Its Applications; Kluwer Academic Publishers: London, UK, 1994.

49. Van Laarhoven, P.J.M.; Pedrycz, W. A fuzzy extension of Saaty's priority theory. Fuzzy Sets Syst. 1983, 11, 229-241.

50. Wang, Y.M.; Elhag, T.M.S.; Hua, Z. A modified fuzzy logarithmic least squares method for fuzzy analytic hierarchy process. Fuzzy Sets Syst. 2006, 157, 3055-3071.

51. Buckley, J.J. Fuzzy hierarchical analysis. Fuzzy Sets Syst. 1985, 17, $233-247$.

52. Chang, D.Y. Applications of the extent analysis method on fuzzy AHP. Eur. J. Oper. Res. 1996, 95, 649-655.

53. Xu, R. Fuzzy least-squares priority method in the analytic hierarchy process. Fuzzy Sets Syst. 2000, 112, 359-404.

54. Mikhailov, L. A fuzzy approach to deriving priorities from interval pair wise comparison judgments. Eur. J. Oper. Res. 2004, 159, 687-704.

55. Csutora, R.; Buckley, J.J. Fuzzy hierarchical analysis: The Lamda-Max method. Fuzzy Sets Syst. 2001, 120, 181-195.

56. Ross, T.J. Fuzzy Logic with Engineering Applications; McGraw-Hill, Inc.: New York, NY, USA, 1995.

57. Pan, N.F. Fuzzy AHP approach for selecting the suitable bridge construction method. Autom. Constr. 2008, 17, 958-965.

58. Vahidnia, M.H.; Alesheikh, A.A.; Alimohammadi, A. Hospital site selection using fuzzy AHP and its derivatives. J. Environ. Manag. 2009, 90, 3048-3056.

59. Amos, W.A. Costs of Storing and Transporting Hydrogen; National Renewable Energy Laboratory: Denver, CO, USA, 1998.

60. İbrahim, H.; Ilincaa, A.; Perron, J. Energy storage systems-Characteristics and Comparisons. Renew. Sustain. Energy Rev. 2008, 12, 1221-1250. 
61. Chalk, S.G.; Miller, J.F. Key challenges and recent progress in batteries, fuel cells, and hydrogen storage for clean energy systems. J. Power Sources 2006, 159, 73-80.

(C) 2013 by the authors; licensee MDPI, Basel, Switzerland. This article is an open access article distributed under the terms and conditions of the Creative Commons Attribution license (http://creativecommons.org/licenses/by/3.0/). 